\title{
Do Foreigners Pay Higher Rents for the Same Quality of Housing in Geneva and Zurich?
}

\author{
Andrea Baranzini ${ }^{a}$, Caroline Schaerer ${ }^{a}$, José V. Ramirez ${ }^{a}$ \\ and Philippe Thalmann ${ }^{\text {b }}$
}

JEL-Classification: R31, R52, D63

Keywords: housing market, rental market, hedonic model, discrimination, prejudice

\section{Introduction}

Residential segregation and discrimination have been extensively studied in the United States, which exhibits large proportions of ethnic minorities, often very concentrated in well-defined areas. In Western Europe, the problem of ghettos in which more than 70 per cent of the area's inhabitants are of a minority group is scarcer. In fact, Western European countries often comprise a mix of different minority populations (see Huttman, 1991, and Harrison, Law and Phillips, 2005). Furthermore, minorities are more identified by geographic origin than by ethnicity. Indeed, international migration is high and integration and assimilation may be less rapid than in the USA.

a Geneva School of Business Administration (HEG-Ge), Center for Applied Research in Management (CRAG), University of Applied Sciences of Western Switzerland (HES-SO), 7 route de Drize, CH-1227 Carouge, Geneva, Switzerland. Andrea.Baranzini@hesge.ch; Jose.Ramirez@hesge.ch; Caroline.Schaerer@hesge.ch

b Swiss Institute of Technology Lausanne (EPFL), Research Group on the Economics and Management of the Environment (REME), Station 16, 1015 Lausanne, Switzerland. Philippe.Thalmann@epfl.ch

Acknowledgements: We are grateful for financial support from the Swiss National Science Foundation, National Research Programme NRP 54 "Sustainable Development of the Built Environment". We thank the Swiss Federal Statistical Office for providing the data of the 2000 Swiss Population Census; the Geneva and Zurich Cantonal Offices for protection against noise for the noise data; the Information System of the Geneva Territory (Système d'Information du Territoire Genevois, SITG) and the Zurich GIS-centre of the office of land use regulation and measurement (GIS-Zentrum des Amtes für Raumordung und Vermessung des Kantons Zürich, ARV) for providing the GIS data. A special thank to Eva Robinson for excellent assistance support in calculating GIS variables. None of these institutions or persons is responsible for or endorses in any way the contents of this paper. 
Switzerland is one of the OECD countries with the highest proportion of foreigners, which amounts to about one-fifth of total population. The foreign population is however quite unevenly distributed over the Swiss territory, with the highest proportions being located in the urban cantons. In 2006, the share of foreign population ranges from a maximum of 37.3 per cent in the Geneva Canton to a minimum of 8.5 percent in the Canton of Uri (OFS, 2006). In addition, the composition of resident foreign population is often related to the different linguistic regions of the country. Broadly speaking, relatively more foreigners from a Latin language country are located in the French-speaking part of Switzerland, while residents from Germanic language countries and ex-Yugoslavia are more represented in the German-speaking parts of Switzerland. Finally, Italians immigrate mostly to the Italian-speaking part of Switzerland (see Huissoud, Stofer and Cunha, 1999, for a description of the distribution of foreign population in the different regions of Switzerland). Schuler (1999) explains that Switzerland has experienced two periods of high immigration flows since 1950, the first from 1958 to 1967 , and the second during the 1980s. In both migration waves, immigrants can be distinguished based on their origin and socio-economic category. Indeed, immigrants from Western and Northern European countries possess a relatively high level of education and training, while migrants from Southern European countries and lately from ex-Yugoslavia and Turkey, own comparatively lower socio-economic assets. SCHULER (1999) specifies that immigration in Switzerland has been highly influenced by foreign policy measures such as the types and quotas of residence permits. With respect to the international literature, which mostly refers to the USA, analyzing discrimination and segregation in a European country has therefore to account for several peculiarities of its migration flows and foreign population, such as education level or type of residence permit.

Geographic segregation occurs when the proportions of inhabitants belonging to different groups defined by some characteristics (e.g. origin or education level) vary significantly by area. This might be the result of voluntary clustering or deliberate exclusion. Economic discrimination arises when market transactions cease to be anonymous (the same price for all) and market actors demand different conditions from or exclude some types of customers or suppliers. YINGER (1978) recommends distinguishing between "discrimination", defined as a behaviour against an individual, and "prejudice", which refers to an attitude towards a group of individuals. According to this terminology, price discrimination in the rental housing market arises when landlords charge a higher rent to some socioeconomic categories of individuals (e.g. foreigners). This phenomenon is referred to as a "household effect". On the other hand, prejudice against a particular 
group occurs when dwelling rents are influenced by the socio-economic composition of the neighbourhood. This price differential at the neighbourhood level is referred to as a "neighbourhood effect". Prejudice could co-exist with discrimination. Indeed, both are mutually reinforcing and lead to the same outcome, which is segregation (ZABEL, 2008). Of course, segregation is a condition for the neighbourhood effect.

It is interesting to analyse segregation, prejudice and discrimination in Switzerland for two main reasons. Firstly, as already mentioned, this country has a high proportion of foreign population of diverse origins and with different levels of human capital assets. The second reason is the high proportion of rental housing, which represents about two thirds of the whole housing market, more than in any other industrialised country (OFL, 2003). Rental markets are presumably more inclined to discrimination, because they imply a continuous relationship between the landlord and the tenant. From this point of view, assessing discrimination on the Swiss housing market resembles more the kind of discrimination found on labour or mortgage markets than on the property market.

In spite of these arguments and the sometimes fierce political debates about immigration and the presence of foreigners in Switzerland, the Swiss literature on residential segregation and discrimination is, to our knowledge, relatively scarce even at a descriptive level. Huissoud, Stofer, Cunha and Schuler (1999) study segregation in major Swiss urban areas, among which Geneva and Zurich. Heye and Leuthold (2004) analyze residential segregation in the city of Zurich and its agglomeration. They are primarily concerned with the dynamics of migration in urban areas in relation to the socio-cultural neighbourhoods. Again for the Canton of Zurich, Arend (1991) studies the housing segregation of underprivileged guest workers from poorer European countries. Residential discrimination is even less documented and studied. There are only some consulting reports on housing market tendencies that highlight basic linkages between foreigners and housing or rental prices (AREND, 1991; WANNER, 2004; WüEST \& PARTner, 2007).

The main difficulty with identifying prejudice and discrimination on a housing market is that they are just two of many factors affecting prices or rents. Just as it is hard to verify that a woman earns a lower wage because she is a woman and not because she is, say, less qualified for the job, it is hard to verify that a foreign household pays a higher rent than a Swiss would or does for an apartment of same quality. However, the hedonic approach is precisely designed to identify the respective contribution of all factors affecting rents, including possibly the characteristics of the tenant or buyer. In this paper, we thus propose to apply the hedonic approach to test for the presence of prejudice and discrimination 
on the rental housing markets of the Zurich Municipality and of the canton of Geneva. We will follow authors like Kiel and Zabel (1996), Zabel (2008), Knight (2008) and Kestens, Thiérault and Des Rosiers (2004) and extend the basic hedonic model in order to test for the existence and the importance of household and neighbourhood effects.

The structure of the paper is the following. Section 2 examines the pertinence of the hedonic approach in assessing the consequences of discrimination and prejudice. In Section 3, we discuss our dataset and the main characteristics of the foreign populations in Geneva and Zurich, as well as their rental markets. The empirical implementation and results are presented in Section 4. Section 5 concludes and suggests further areas of research.

\section{Applying Hedonics to Assess Discrimination and Prejudice}

Based on the seminal work of Rosen (1974), the hedonic approach assumes that heterogeneous goods are valued for their utility-bearing characteristics. This implies that the house price or the dwelling rent $P$ is determined by the implicit price of the vector of house or dwelling characteristics, $z: P=P(z)$. This is the general form of the hedonic price model (see e.g. PalmQuist, 1999; for a recent survey see TAYLOR, 2008). The characteristics are often decomposed in a vector of structural (for example the number of rooms), accessibility (e.g. proximity to public transportation), environmental quality (such as noise) and neighbourhood (for example proportion of green areas) variables. Given the key assumption that the housing market is competitive (see FrEeMAN, 1993), estimators of hedonic models are quite reluctant to include personal characteristics, because competitive market prices are independent of individual buyers and sellers. Therefore, the race or any other characteristic of the buyer should not affect the price of houses. However, the rents and prices for housing contracts are obviously not always set on competitive markets and thus, when there is discrimination, some characteristics of the buyer, such as race or income, can affect the price of the house. The neighbourhood socio-demographic composition could also be considered as a variable defining the quality of the neighbourhood and thus have an influence on prices. When estimating hedonic prices or rents, it seems therefore pertinent to take into account and test the importance of the household and neighbourhood characteristics (see Kiel and Zabel, 1996; Zabel, 2008).

The literature emphasises several reasons that may explain why different socioeconomic groups may pay different prices for structurally identical rental units in similar neighbourhoods. Those reasons can arise from the supply or demand 
side of the housing market. Since this literature mostly refers to the USA, we refer thereafter to discrimination of the majority against the minority.

On the supply-side, pure discrimination occurs when majority landlords and real estate brokers are reluctant to rent to minority households and agree to do so only if they are paid a bribe (see e.g. BECKER, 1957). Another reason of price discrimination, highlighted by YINGER (1978), could be related to a lower price-elasticity of demand by minority households, which implies that profit-maximizing sellers will charge them a higher price. KING and Mieszkowski (1973) suggest that the cost of providing housing to nonwhites in the USA might be relatively greater due to relatively larger family sizes and weaker economic conditions (i.e. higher uncertainty of rent payments). Arend, Kellerhals Spitz and Mächler (1990) also argue that dwelling renters might be reluctant to lease their dwelling to foreigners in Switzerland, because of higher uncertainty of rent payments particularly for foreigners occupying low wage jobs - and because they fear that renting to foreigners might reduce the value of their building.

On the demand side, KING and MieszkowsKi (1973) state that immigrants will tend to pay more than residents for dwellings of identical quality since they are less familiar with the market. Therefore, as the cost of searching can be important, new migrants might rent a less than ideal dwelling and envisage subsequent searches once established. Similarly, Knight (2008) emphasizes the role of the conditions of transactions on property prices. He argues that the observed transaction price is the result of negotiations and might depend on sellers' and buyers' market information and their relative bargaining strength. Minority households may therefore pay more because their bargaining power is lower. In the same vein, Harding, Knight and Sirmans (2003) estimate the effects of bargaining on selling prices and find that women, first time and relatively poorer buyers have less bargaining power. Another demand-side explanation is related to different preferences for the socio-economic characteristics of the neighbourhood (see Schelling, 1971). For instance, ZABEL (2008) argues that if whites prefer to live among whites, they are willing to pay a premium for living in areas predominantly populated by white households. Respectively, if nonwhites prefer to live in integrated neighbourhood rather than in ghetto areas, then nonwhite households will be willing to pay a premium for a similar dwelling in integrated areas.

Given the different reasons that could trigger price differentials among different socio-economic individuals, GALSTER (1977) argues that including a racial variable in the hedonic price regression does not allow identifying differences between "taste for segregation" from the "taste for ghetto environment". He therefore assumes that ghetto holds specific features in the eyes of nonwhites which 
are not present in racially integrated areas. YINGER (1978) tackles this issue in his "border model", by allowing house prices differentials due to household and neighbourhood racial effects to vary across submarkets, defined a priori according to the percentage of nonwhite inhabitants. Then, the "taste for segregation" is directly observable if the household effect varies across the different submarkets. Evidence of a neighbourhood effect would also directly appear in case housing prices in black areas prove to be relatively higher than housing prices in predominantly white areas. This model is applied by KIEL and ZabeL (1996) and Myers (2004), who identify the house price differentials that are due to racial discrimination and neighbourhood effects. Kiel and Zabel (1996) estimate a hedonic model for the US cities of Denver, Philadelphia and Chicago, including a dummy to control for nonwhite household's head and racial neighbourhood characteristics, i.e. the percentage of nonwhite individuals in the neighbourhood at the census tract ${ }^{1}$ level. This specification allows identifying whether nonwhite households are discriminated and have to pay a premium to overcome a racial barrier, as well as possible price differentials due to the racial composition of the neighbourhood, i.e. prejudice. They find a price discount for nonwhite households and a negative impact of the percentage of nonwhites in the neighbourhood. They also report that the price discrimination coefficient is greatly overvalued when racial neighbourhood variables are omitted. Myers (2004) uses sub-samples from the national American Housing Survey in 1985, 1989 and 1993. As Kiel and Zabel (1996), she differentiates between three sub-markets according to their racial composition (i.e. white, integrated and black). She estimates a fixed effect model and finds evidence of significant price discrimination and racial prejudice in the property market.

From the previous studies, it results that neighbourhood composition variables are important and have to be accounted for in hedonic studies. However, we emphasize that since the hedonic model just depicts the equilibrium price locus, it is difficult to infer from it whether (if any) price differences are due to discrimination or prejudice forces (see BAJARI and KAHN, 2005 and 2008). Moreover, there is no clear-cut definition in the literature of what households consider as their neighbourhoods. In empirical studies, neighbourhoods are often defined $a$ priori based on the administrative boundary (city, zip codes, census tracts, census block, block groups) for which the data are available. In that perspective, KIEL

1 A census tract is an administrative area defined by the United States Census Bureau. It includes between 1500 and 8000 inhabitants, with an average of 4000 inhabitants. Myers (2004) reports that a census tract with 4000 inhabitants would represent about 1527 houses and about 100 city blocks of 15 houses each. 
and ZABEL (2004) estimate a property-hedonic model including neighbourhood variables at three different levels (cluster, census tract and metropolitan statistical area, MSA $^{2}$ ). Myers (2004) highlights that neighbourhoods' definition and size have an impact on residential segregation results. She argues that defining neighbourhoods that are too large and too heterogeneous may increase the error in categorizing sub-markets and therefore increase the error in the estimated neighbourhood characteristics implicit prices. However, an excessively small delimitation of a neighbourhood might also introduce an error, for example by misclassifying an integrated area as a ghetto. She nevertheless concludes that small neighbourhoods present fewer problems than too large ones.

\section{Context, Data and Descriptive Statistics}

Before turning to the analysis of the impact of discrimination and prejudice in Geneva and Zurich, we characterise neighbourhoods in the two areas in terms of population's socio-economic composition and density. Our main source of information is a detailed database from the most recent Swiss Population Census 2000. This database includes information on all individuals and households as well as on all dwellings and buildings. Concerning the individuals, it provides information about the gender, the number of children, the educational attainment, or the type of job. However, the dataset does not provide information about income and religion. From the original database we dropped the individuals working in international organizations due to their special status, individuals with unknown origin and with unknown education level. Note moreover that due to data availability of road traffic noise level (see below) we restrict our analysis of the canton of Zurich to the Zurich Municipality. Indeed, precise measure of road traffic noise level is available for the whole canton of Geneva, but only for the Municipality of Zurich. Therefore, for comparative purposes, we refer to the whole canton of Geneva (thereafter Geneva), that extends on $245 \mathrm{~km}^{2}$ with 352684 inhabitants, and to the Municipality of Zurich (thereafter Zurich), of a size of $92 \mathrm{~km}^{2}$ and 338239 inhabitants.

The proportion of foreigners in Geneva and Zurich amounts to 33 per cent and 28 per cent, respectively. As already mentioned, aside their nationality, another

2 The United States Census Bureau defines the Metropolitan Statistical Area (MSA) as a statistical area that includes at least one urban area of 50000 people or more, plus the territory adjacent to it with which it has a high degree of social and economic relations. 
important characteristic differentiating individuals is of course their income level. However, since the Census does not collect data on income, we decided to focus on the achieved education level, which can be thought to be correlated with income and social status. Based on the available information, we differentiate individuals based on "low" vs. "high" education attainments. Individuals with low education level are defined as those who do not possess any education degree or just completed the compulsory school, a general cultural school or a school preparing to a professional education. Individuals with a high education attainment level are all the others, i.e. those with a secondary (e.g. training school or high school diploma) or a third degree (e.g. university diploma) education level. The proportions of low education individuals are almost the same in the two areas, about 30 per cent of the working age population (16 years and older), of whom about 17 per cent are Swiss and 13 per cent foreigners. The remaining 70 per cent high education population is composed of 57 per cent Swiss and 13 per cent foreigners. Seen differently, 23 per cent of the Swiss and 46 per cent of the foreigners have a low education level. We also considered using the degree of qualification required for the occupied job as a substitute for income as in Huissoud, Stofer, Cunha and Schuler (1999). However, we prefer to work with the educational attainment since the job's level of qualification is available only for the active population.

The Census allows for calculating population densities and socio-economic composition indicators at two levels of aggregation: the hectare and at a higher aggregation level census tract that we call "district". In our sample, we have 48 districts and 7322 hectares for Geneva and 12 districts and 4345 hectares for Zurich. In Geneva, the mean population by district is 7348 inhabitants, with a standard deviation of 10647 inhabitants, while in Zurich the mean population by district is 28187 individuals, with a standard deviation of 11481 . By hectare, the mean population amounts to 48 (78) inhabitants in Geneva (Zurich), with a standard deviation of 81 (138) individuals. In Geneva, the mean number of buildings per district (hectare) amounts to 1164 (7), while in Zurich, the mean number of buildings per district (hectare) amounts to 3585 (13). Given the relatively large variability of the districts population, performing the analysis at the hectare level is more interesting as it allows capturing more precisely the distribution of the population in the studied areas (see Myers, 2004). Nevertheless, for comparison purpose, we present also the variables defined at the district level.

3 For the Canton of Geneva, the districts correspond to Municipalities of the Canton plus the four subdivisions of the Geneva Municipality used by the Statistical Office. For Zurich, the districts corresponds the Zurich Municipality subdivisions known as Kreise. 
Using the Census data, we have calculated the following socio-economic composition variables: i) the share of foreigners in the full population (i.e. including children and under working-age individuals); ii) the share of individuals with low education level in the full working-age population (16 years and older); and iii) the shares of foreigners with low and high education levels in the full working-age population.

Figures 1 and 2 illustrate the first two statistics at the district and hectare levels (see Schaerer and Baranzini (2008) for a detailed description and an analysis using segregation indices). We observe a greater variability of the distribution of foreign population and of highly educated individuals when measured at the hectare level as compared with the district. In Figure 1, we also notice that share of foreigners can attain 40 to 45 per cent of the total population, especially in the districts near the city centres. This proportion can even exceed 60 per cent in some hectares. Of course, given the small surface and number of inhabitants, we cannot call those hectares "ghettos". See also OCSTAT (2005) for a detailed description of the relative concentration of foreigners by origin in the canton of Geneva.

Comparing Figure 1 with Figure 2, there appears at first glance an inverse relationship between the presence of foreigners and the level of educational attainment: the higher the share of foreigners, the lower the educational attainment level. Indeed, the correlation between the share of foreigners and the share of high education individuals at the district level amounts to -0.91 per cent in Zurich $(-0.73$ per cent in Geneva) and to -0.46 per cent at the hectare level $(-0.22$ per cent in Geneva).

In order to implement the hedonic approach presented and discussed in Section 2, we need information on dwellings and buildings characteristics, as well as data measuring the neighbourhood quality, in addition to the population's socioeconomic characteristics. Concerning buildings and dwellings characteristics, they are reported in the 2000 Swiss Population Census. However, since the same dwelling will appear more than once in the dataset for each household composed of more than one individual, we keep the household heads only. ${ }^{4}$ As we focus on rents, we drop the owner-occupants, the members of a housing cooperative, the

4 The household head is defined according to the following criteria, by order of priority: 1) an older individual is preferred over a younger one; 2) a full-time working individual is selected over a part-time worker, an unemployed, a retired individual, a student, or someone who is not in the labor force; 3) an individual occupying an executive job is chosen over an individual with an independent activity, an intermediate-level job, an employee, a factory worker, or an apprentice. 


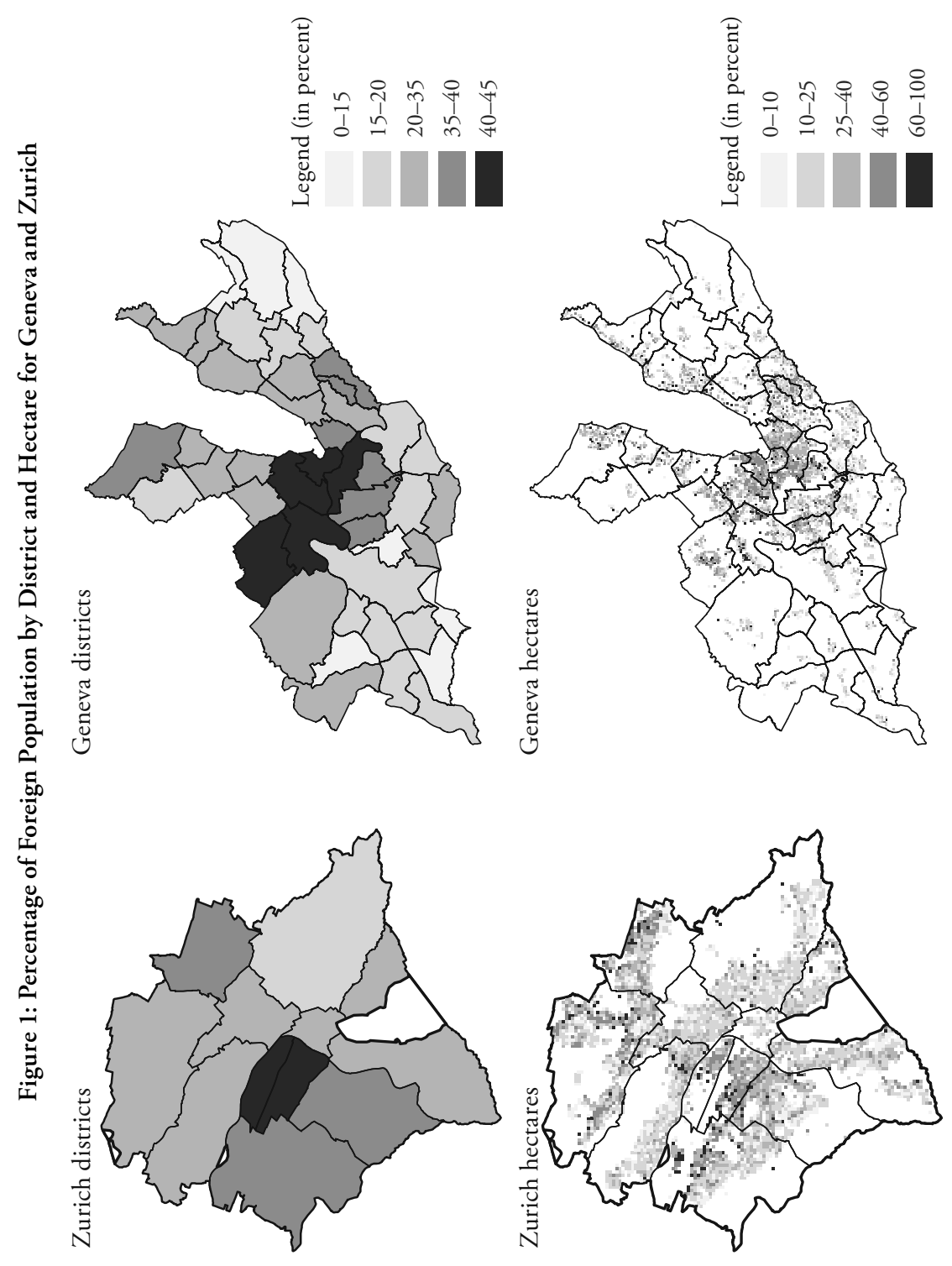




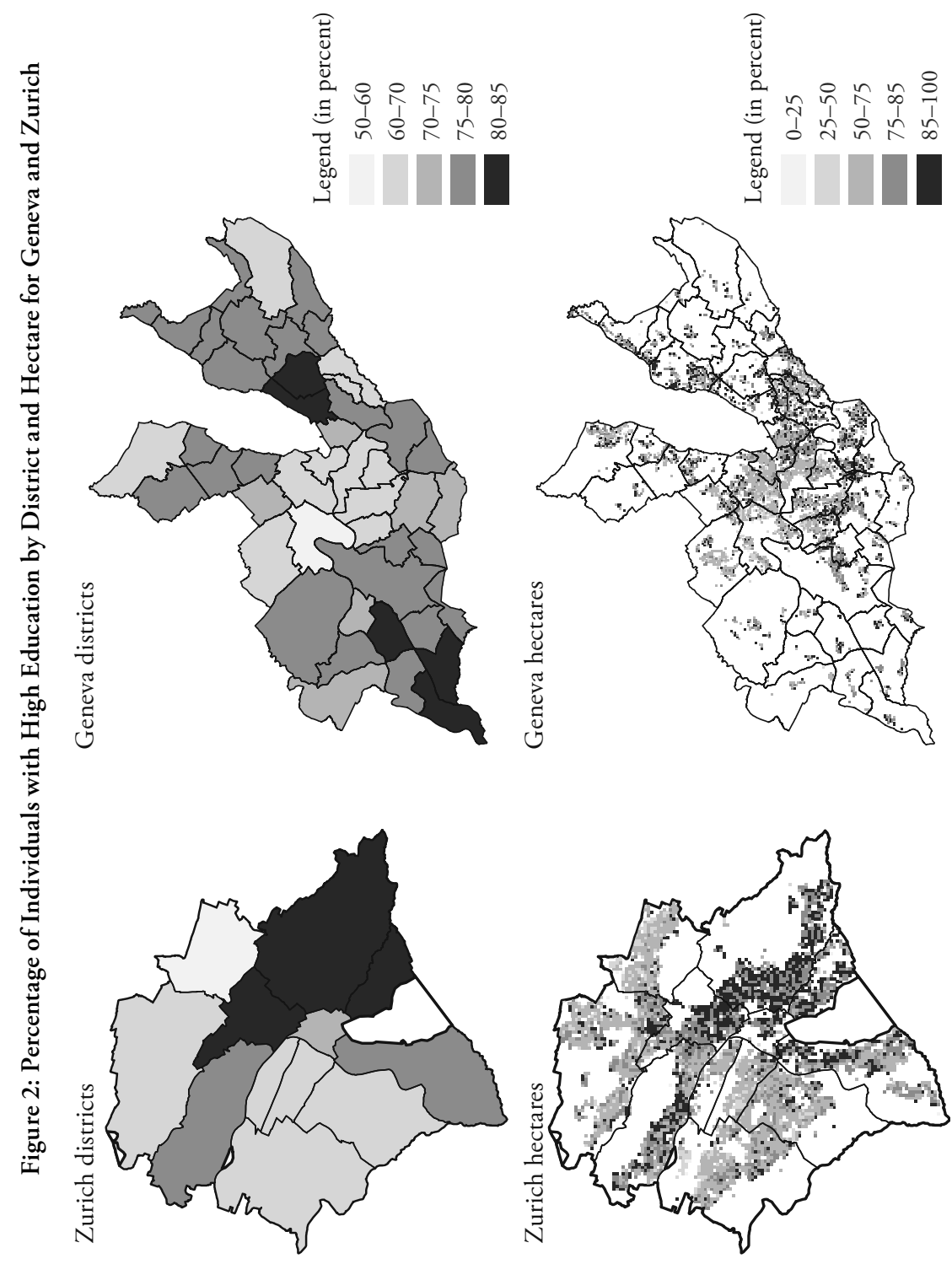


occupants of single family houses, and the holders of special rental contracts (i.e. holders of a free-rent dwelling, holder of service dwelling, or of a farming lease) from the dataset. To this dataset we add several variables that measure environmental and accessibility characteristics of the building and the neighbourhood. Therefore, starting from the Census information on 352684 individuals for Geneva and 338239 individuals for Zurich, merging all the information, dropping observations for which noise exposure is unreliable ${ }^{5}$, as well as a few outliers, we obtain two final samples of 42162 observations for Geneva and of 26489 observations for Zurich, which are then used to implement the hedonic model. Table 1 provides descriptive statistics for the two samples.

The neighbourhood composition variables are those calculated and presented above based on the whole Census sample. However, since in Table 1 we consider household heads with complete information only, the statistics differ slightly from the numbers previously presented. We observe that the mean percentage share of foreigners per hectare is higher in Geneva (about 40 per cent) than in Zurich (about 30 per cent). The mean share of high education foreigners per hectare is also greater in Geneva than in Zurich, but the mean share of high education foreigners per hectare exceeds that of low education foreigners in Zurich. The reverse is true in Geneva.

Concerning the characteristics of household heads, about 37 per cent are of foreign nationality in the Geneva sample, out of which 18 per cent have a low education level. In Zurich, the proportion of foreign household heads amounts to 25 per cent, of whom 11 per cent have a low education level.

The mean net monthly rent in 2000 is somewhat lower in Geneva (about CHF 1082) than in Zurich (about CHF 1221 ), but the rent distribution is broader in Geneva. ${ }^{6}$ The Zurich sample contains slightly older buildings than the Geneva sample: about 40 per cent of the buildings were constructed before 1946 in Zurich, while only about 29 per cent in Geneva. Conversely, the share of buildings constructed between 1960 and 1980 is higher in Geneva than in Zurich. With a mean number of rooms of about 3 , for a mean surface per room of $26 \mathrm{~m}^{2}$,

5 Observations for which the noise exposure lies above $75 \mathrm{~dB}(\mathrm{~A})$ are dropped because noise measures at those levels are unreliable (see acoustic literature, e.g. Miedema and Vos, 1998; MieDEMA and OUdSHOORN, 2001). In the same vein, we restrict our samples to the observations for which the noise levels exceeds or equals $55 \mathrm{~dB}(\mathrm{~A})$ during the day. These thresholds correspond to the planning regulations for housing areas in Swiss law (see Swiss Noise Abatement Ordinance, 1986, art. 43). See Baranzini, Schaerer, Ramirez and Thalmann (2006) for a discussion of the use of scientific vs. subjective noise measures in hedonic models.

6 In June 2008, CHF $1=$ USD 0.96 or EURO 0.62. The OECD PPP exchange rates for 2007 are CHF $1=$ USD 0.60 or EURO 0.52 . 
the size of the dwellings are about the same in the two urban areas. ${ }^{7}$ However, the mean surface available per inhabitant is smaller in Geneva than in Zurich, suggesting that the mean size of the households is larger in Geneva.

The percentage of buildings owned by a public entity (municipality, canton or confederation) is about the same in the two cities, while the share of privately owned buildings appears to be higher in Zurich (53 per cent against 34 per cent in Geneva). The remaining buildings belong to institutional owners, i.e. insurances, pension funds and real estate companies. Interestingly, about 56 per cent of the households have been living in the same dwelling for at least 5 years, which suggests a low dwelling turnover rate. Actually, in Schaerer, Baranzini, RamiREZ and Thalmann (2007), we showed that the mean duration of residence in the same dwelling is of about 13 years in Zurich, respectively about 15 years in Geneva, with a very large distribution.

The Information System of the Geneva Territory (SITG) and the GIS-centre of the Zurich office of land use regulation and measurement (ARV) provide two very rich and well-developed geographic information systems (GIS) databases, which we use to define the variables related to the buildings location. Firstly, we calculate accessibility variables, which measure precisely the distance of the building to environmental amenities and main public infrastructures, such as the city centre, the nearest urban park and the nearest public transportation stop. Secondly, we define several neighbourhood variables (at the district level) quantifying the percentage of different land-use characteristics, such as the percentage of tree-covered area and the percentage of urban parks. As reported in Table 1, the accessibility variables to the different land uses have all a low mean, which illustrates that the studied regions are relatively small and dense.

Finally, from the Cantonal offices of protection against noise of Geneva and Zurich, we obtained the yearly averaged daytime traffic noise, expressed in the A-weighted decibel scale $(\mathrm{dB}(\mathrm{A}))$. The data refer to the level of noise caused by road traffic, measured at some fixed points, and then extrapolated for each facade of the buildings. The daytime noise level represents the equivalent continuous noise level averaged over 15 hours. From Table 1, we note that the mean exposure to daily road traffic noise amounts to $65.7 \mathrm{~dB}(\mathrm{~A})$ in Geneva and to $67.6 \mathrm{~dB}(\mathrm{~A})$ in Zurich, more than the legal limit of $60 \mathrm{~dB}(\mathrm{~A})$ set in the Swiss noise regulation for residential areas (Swiss Noise Abatement Ordinance, art. 43). However, the average noise level in our sample may overestimate the effective average noise

7 The number of rooms includes living room and bedrooms, but excludes the kitchen and bathrooms. 


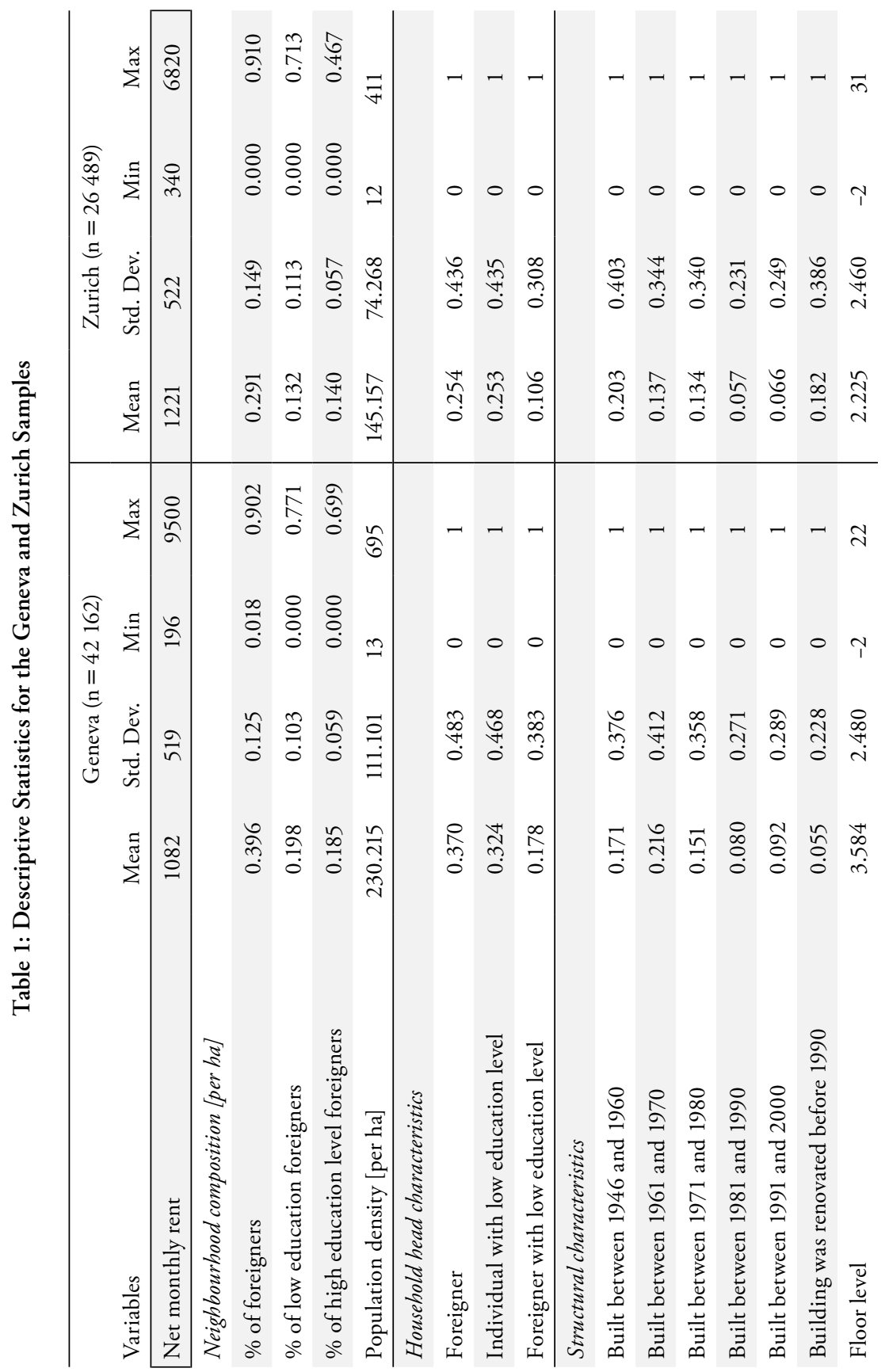




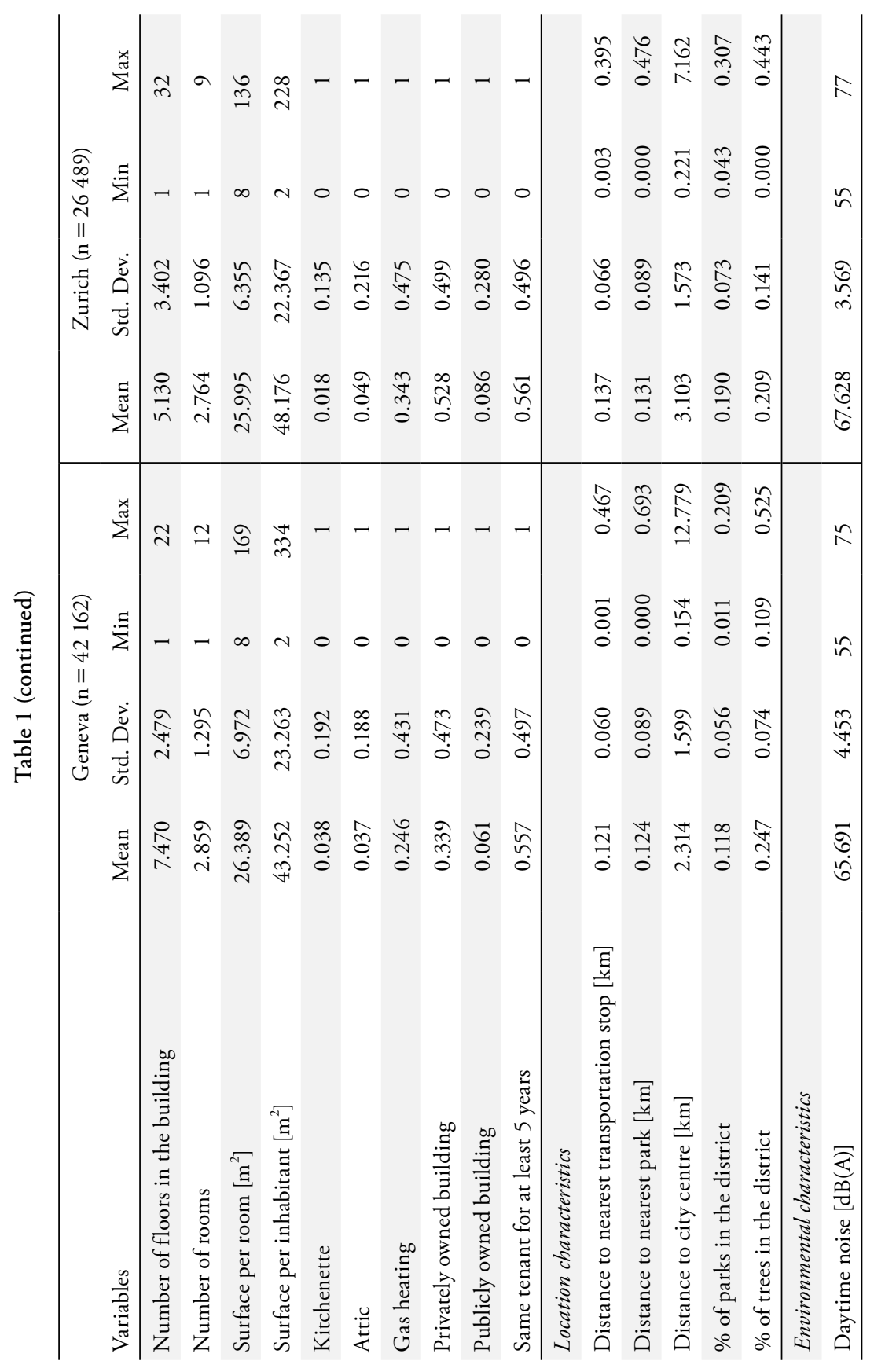


exposure in the regions, because noise is often measured where the road traffic noise is suspected to be high.

\section{Empirical Implementation and Results}

In this section we test for discrimination and prejudice and estimate their impact in the housing markets of Geneva and Zurich. We first estimate a traditional hedonic model (Model 1) that does not include any individual characteristics of the household's head. Then, as in Kiel and Zabel (1996) and Myers (2004), in Model 2 we introduce the households' characteristics at two different levels. Firstly, we introduce a dummy to account for nationality. This variable will be used to test for the presence of discrimination. Indeed, if the coefficient for this dummy is statistically significant and positive, a foreigner is paying a higher rent, for a dwelling possessing the same characteristics as those of a Swiss. Secondly, we define a variable measuring the share of foreigners in the hectare where the building is located. If the coefficient of this latter variable is statistically significant and negative, this hints at prejudice, meaning that tenants are willing to pay a premium to live in neighbourhoods with fewer foreigners. However, we should note like HARris (1999) that neighbourhoods might also be disliked due to other neighbourhood concerns, such as poverty rate, crime rate, deteriorating buildings, ineffective public schools and social problems, which could be correlated with the socio-economic mix. A similar argument is raised by BAYer Ferreira and McMillan (2007) and Bayer and MacMillan (2008), who argue that households' preferences are heterogeneous depending on a wide range of characteristics, some of which are unobservable even with the richest datasets. Moreover, they state that the households' location choices are non-random and partly influenced by these unobservable choice attributes, which are likely to be correlated with neighbourhood socioeconomic compositions. If this is verified, it would imply that the coefficient associated with the share of foreigners and interpreted as prejudice is biased. We therefore estimate Model 2-fix in which we control for a fixed effect at the district level in order to account for a possible correlation between the neighbourhood composition variable and unobserved neighbourhood quality. The comparison of the coefficients associated with the share of foreigners in Model 2 and Model 2-fix allows us to draw some evidence on the unobserved neighbourhood quality.

Since the theoretical literature does not dictate any functional form for the hedonic price equation, it has to be determined empirically. Linear, semi-logarithmic, log-linear, as well as linear Box-Cox transformations are commonly used 
functional forms. The semi-logarithmic functional form appears to be the most adequate, and therefore our models have the form: ${ }^{8}$

$$
\ln Y_{i}=\alpha+\sum_{e=1}^{E} \beta_{i e} T_{i e}+\sum_{f=1}^{F} \delta_{i f} H_{i f}+\sum_{g=1}^{G} \lambda_{j g} N_{j g}+\mu_{i}
$$

where $\ln Y_{i}$ is the natural logarithm of the 2000 net monthly rent of dwelling $i, T_{i e}$ corresponds to traditional (structural, location, and environmental) characteristic $e$ of dwelling $i, H_{i f}$ stands for attribute $f$ of the household head living in dwelling $i, N_{j g}$ refers to the neighbourhood composition $g$ of the hectare $j$ in which $i$ is located and $\mu_{i}$ is an error term reflecting all the unobservable.

The results of the estimations of Model 1 and its variants are reported in the corresponding columns of Table 2 . The analysis of simple correlation matrices indicates that there are no significant dependencies between the variables, and the variance inflation factor (vif) test confirms that there is no problem of multicolinearity. The three alternative models produce very similar results. They explain about two third of the variance of log rents in Geneva and Zurich.

The comparison of the coefficients of Model 1 with those of the other two models shows that the coefficients are remarkably stable across the models, except for the coefficient associated with the share of foreigners per hectare (see below). Almost all the variables are statistically significant and have the expected sign. Given the semi-logarithmic functional form of the estimated hedonic price equation (1), the coefficients of the continuous variables represent semi-elasticities, i.e. the percentage change in the rent for a given unit change in the independent variables. For example, an additional $\mathrm{m}^{2}$ in the surface per room leads to an increase in the rent by 1.5 per cent in Geneva and 1.3 per cent in Zurich. For the dummy and the discrete variables, the coefficients are not directly interpretable. Indeed, as shown by HALvorsen and PALMQUist (1980), those coefficients must be transformed using the formula $\left(\mathrm{e}^{\beta}-1\right)$ to obtain the percent change in the dependent variable. Therefore, for instance, the private-sector rent differential relative to institutional-owned buildings amounts on average to about 6.5 per cent in Geneva and 12.5 per cent in Zurich.

8 MALPEZZI (2002) highlighted five major advantages of the semi-logarithmic functional form:

(i) The implicit price of a housing attribute is related to the quantity of the other housing attributes; (ii) The coefficients are easily interpretable in terms of semi-elasticities; (iii) It mitigates heteroskedasticity problems; (iv) It can be computed easily; and (v) Some flexibility in the specification of the independent variables can be easily introduced. 


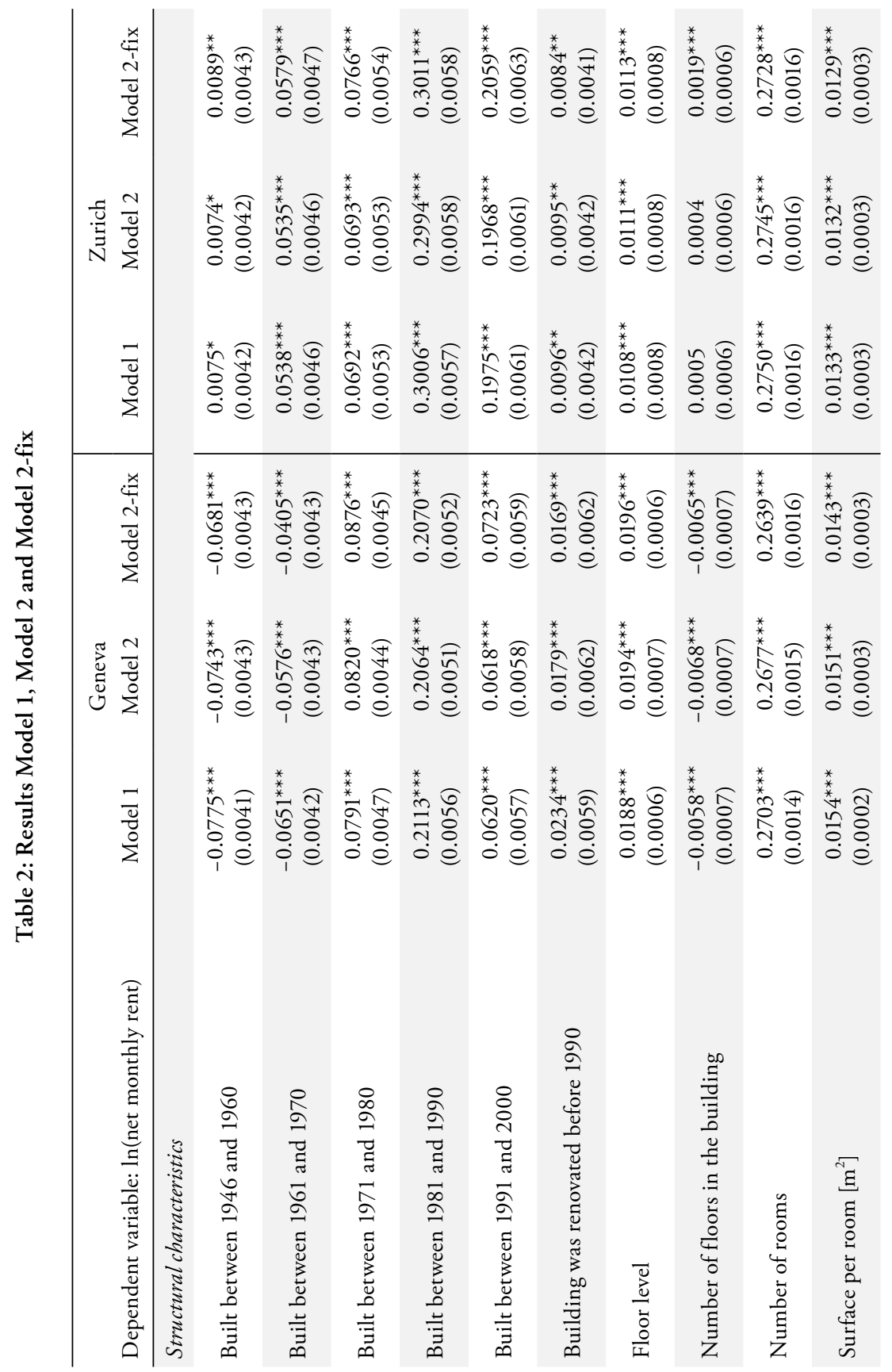




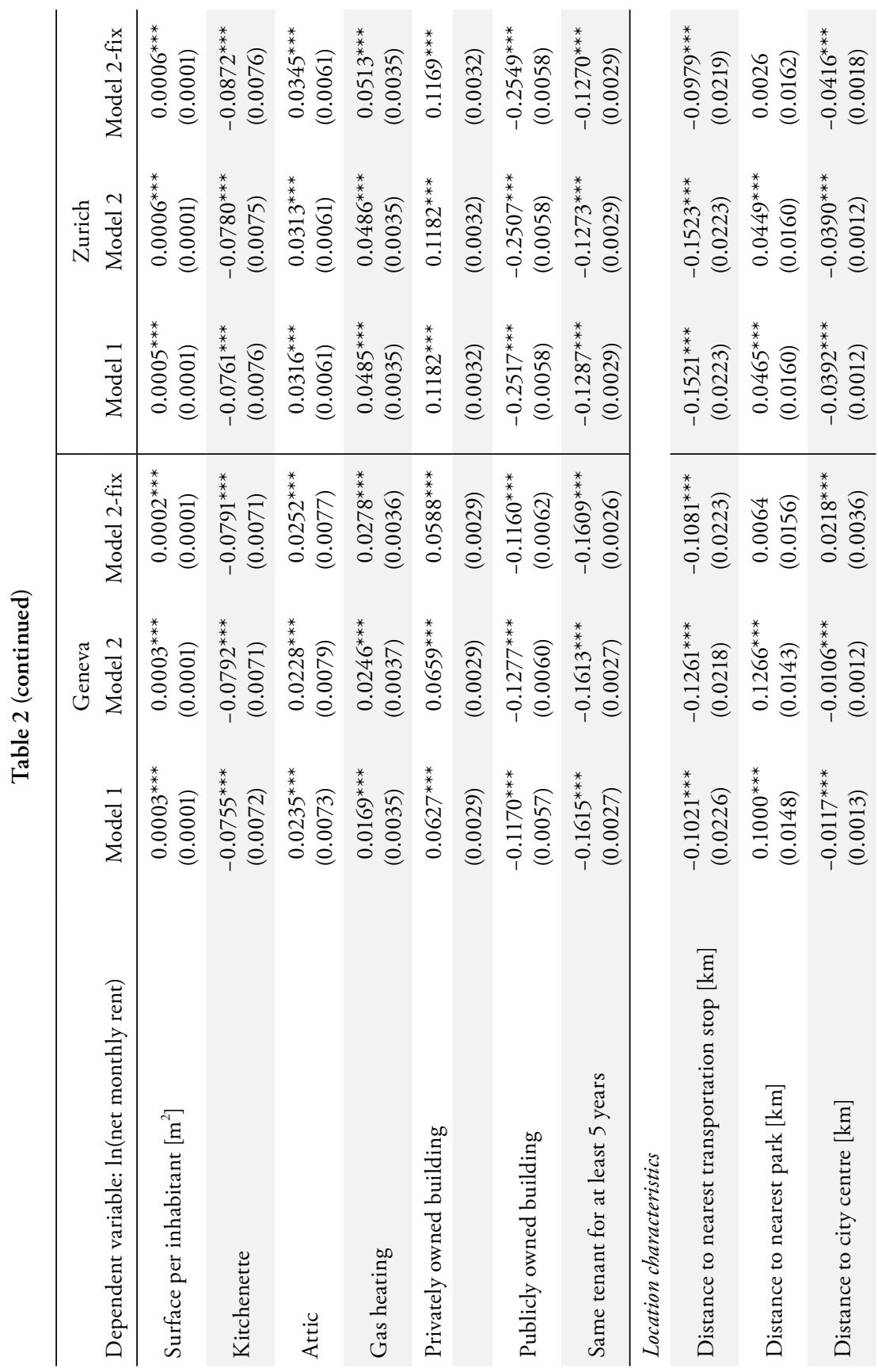




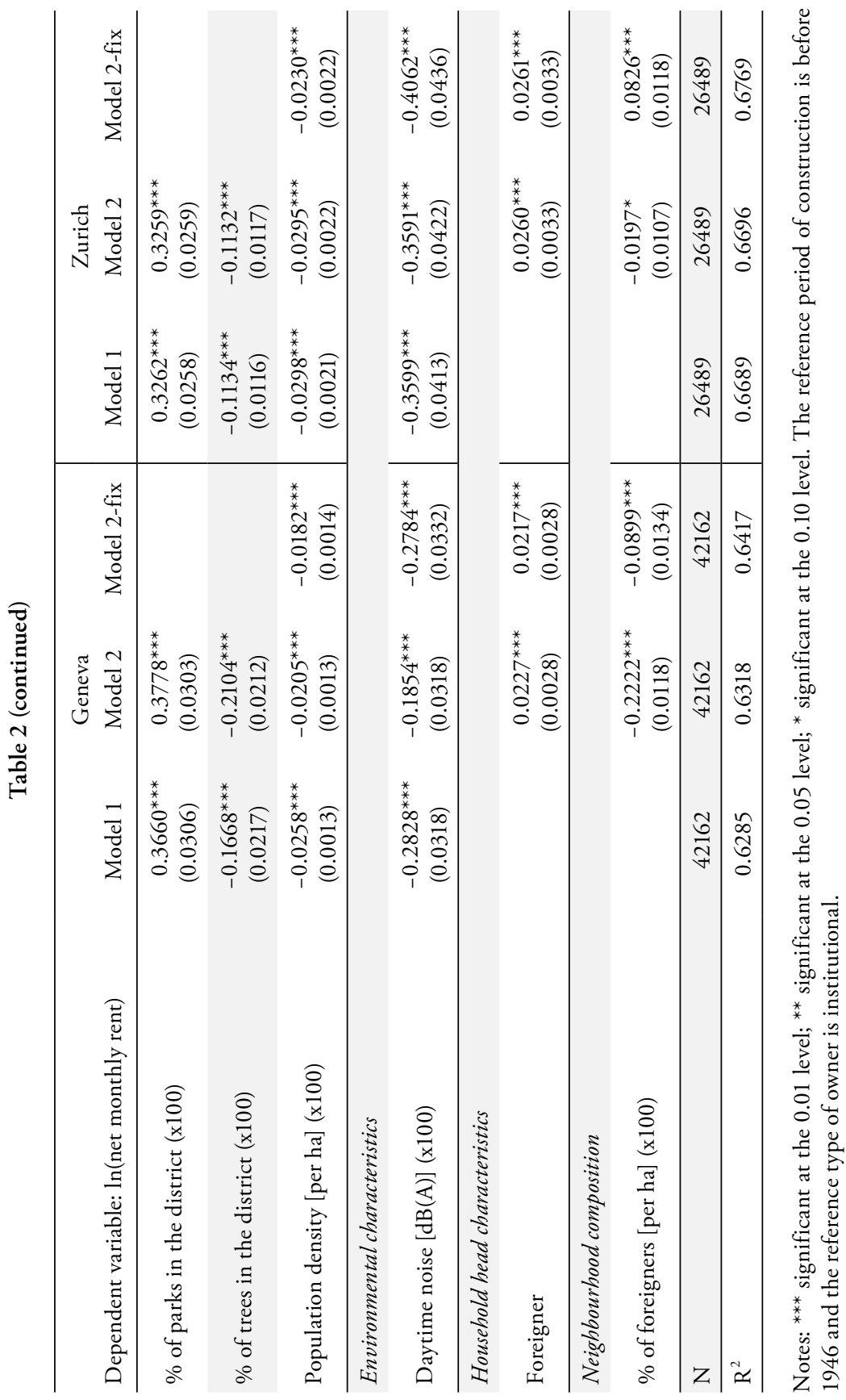


If the same household has been living in the dwelling for the past five years at least, the 2000 rent is about 18 per cent lower in Geneva and about 14 per cent lower in Zurich compared to a more recent lease. This confirms the suspicion that landlords generally seize the opportunity to raise the rent at changes in tenancy (see Thalmann, 1987). Concerning the environmental variables, an additional decibel of road traffic noise during the day decreases the rent by about 0.3 per cent on average in Geneva and 0.4 percent in Zurich. Proximity to the city centre and public transport stops raises rents while proximity to parks lowers them. These results are comparable to the findings from other hedonic studies using alternative databases for the Geneva (see e.g. Baranzini and Ramirez, 2005; Baranzini and Schaerer, 2007) and Zurich markets (see e.g. Banfi, Filippini and Horehajova, 2008; Schaerer, Baranzini, Ramirez and ThalMANN, 2007).

We now turn to the variables related to discrimination and prejudice. In both Geneva and Zurich, the coefficients associated with the nationality of the individual are statistically significant and positive, which hints at discrimination since this implies that for a dwelling with the same characteristics a foreigner pays 2.3 per cent more in Geneva and 2.6 per cent more in Zurich than a Swiss. The statistically significant and negative coefficients associated with the proportion of foreigners in Model 2 suggest prejudice in Geneva and Zurich, since tenants need to be compensated for living in a neighbourhood with a higher share of foreigners. As already discussed, this finding has however to be tested further, since the proportion of foreigners could be correlated with other neighbourhood characteristics (cf. Harris, 1999; Bayer, Ferreira and McMillan, 2007; Bayer and MacMillan, 2008). Indeed, by introducing neighbourhood fixed effects in Model 2-fix, we observe that the coefficients decrease quite considerably in absolute value, from -0.22 to -0.09 in Geneva. This implies that prejudice is over-estimated in Model 2, because part of the neighbourhood unobserved characteristics are correlated with the share of foreigners. This also means that on average the unobserved quality of neighbourhoods populated by higher shares of foreigners is lower than that of neighbourhoods inhabited by a greater proportion of Swiss (which need not imply that overall quality is lower, i.e. including the observed qualities of quietness and accessibility). For Zurich, the coefficient in Model 2-fix becomes even positive, implying that there is no prejudice, but that foreigners are again living in neighbourhoods of lower unobserved quality.

These results should be refined further, since the foreign population in Switzerland is highly heterogeneous in terms of country of origin, education level and type of working permit. Therefore we re-estimate Models 2 and 2-fix by differentiating foreigners between those coming from OECD and non-OECD 
countries. We find that the coefficients of the dummy variables for household heads of OECD and non-OECD origin are statistically the same. The same result is obtained when we differentiate the foreign population according to working permits. Therefore, we conclude that in our context those distinctions are not relevant. Only the distinction based on the education level proves statistically significant, as shown in Table 3. Since the estimated coefficients for all the traditional dwelling characteristics are the same as those reported in Table 2, we report only the coefficients related to the foreign population and the education level. Models 3 and 3-fix are the same as Models 2 and 2-fix, but distinguish between high and low education levels.

From Table 3, we observe again that there is discrimination and prejudice related to the nationality of the households head, but that the education level is also important. For instance, in Geneva (Model 3-fix), a low education foreign household head pays on average 5.2 per cent more (6.8 per cent more in Zurich) for the same dwelling than a Swiss with a low education level. The same holds when comparing individuals with high education: the rent of a foreigner is on average about 2.3 per cent higher than the rent of a Swiss with similar education attainment (for Geneva, $\mathrm{e}^{(0.0909-0.069)}-1$ ). We thus observe that in the Geneva and Zurich housing markets there is discrimination against foreigners, especially the less educated ones.

The comparison of the neighbourhood composition coefficients between Model 3 and Model 3-fix shows an increase in the coefficient for the percentage of low education foreigners. This suggests that foreigners with low education tend to live in neighbourhoods of relatively worse unobserved quality both in Geneva and Zurich. In addition, since the coefficient remains significant and negative in both Geneva and Zurich this suggests prejudice against low education foreigners. On the contrary, the coefficients associated with the percentage of high education foreigners are positive, which implies not only that there is no prejudice towards this category of foreigners, but also that households seem to be willing to pay a premium to live in neighbourhoods populated by a larger share of highly educated foreigners. 
Table 3: Results Model 3 and Model 3-fix

\begin{tabular}{|c|c|c|c|c|}
\hline \multirow[b]{2}{*}{ Dependent variable: $\ln ($ net monthly rent) } & \multicolumn{2}{|c|}{ Geneva } & \multicolumn{2}{|c|}{ Zurich } \\
\hline & Model 3 & Model 3-fix & Model 3 & Model 3-fix \\
\hline \multicolumn{5}{|l|}{ Traditional dwelling characteristics } \\
\hline (same as in Table 2) & $(\ldots)$ & $(\ldots)$ & $(\ldots)$ & $(\ldots)$ \\
\hline \multicolumn{5}{|l|}{ Household head characteristics } \\
\hline Low education foreigner & $\begin{array}{l}0.0530^{* * *} \\
(0.0047)\end{array}$ & $\begin{array}{l}0.0509^{* * *} \\
(0.0047)\end{array}$ & $\begin{array}{l}0.0677^{* * *} \\
(0.0057)\end{array}$ & $\begin{array}{l}0.0659^{* * *} \\
(0.0057)\end{array}$ \\
\hline High education foreigner & $\begin{array}{l}0.0934^{* * *} \\
(0.0046)\end{array}$ & $\begin{array}{c}0.0909^{* * *} \\
(0.0046)\end{array}$ & $\begin{array}{l}0.11096^{* * *} \\
(0.0051)\end{array}$ & $\begin{array}{l}0.1092^{* * *} \\
(0.0050)\end{array}$ \\
\hline High education Swiss & $\begin{array}{l}0.0720^{* * *} \\
(0.0040)\end{array}$ & $\begin{array}{l}0.0690^{* * *} \\
(0.0039)\end{array}$ & $\begin{array}{l}0.09211^{* * *} \\
(0.0042)\end{array}$ & $\begin{array}{l}0.0887^{* * *} \\
(0.0041)\end{array}$ \\
\hline \multicolumn{5}{|l|}{ Neighbourhood composition [per ha] } \\
\hline$\%$ of low education foreigners (x100) & $\begin{array}{l}-0.3930^{* * *} \\
(0.0139)\end{array}$ & $\begin{array}{c}-0.2980^{* * *} \\
(0.0157)\end{array}$ & $\begin{array}{l}-0.3219^{* * *} \\
(0.0143)\end{array}$ & $\begin{array}{l}-0.2534^{* * *} \\
(0.0159)\end{array}$ \\
\hline$\%$ of high education foreigners (x100) & $\begin{array}{l}0.4966^{* * *} \\
(0.0241)\end{array}$ & $\begin{array}{l}0.4907^{* * *} \\
(0.0245)\end{array}$ & $\begin{array}{l}0.9178^{* * *} \\
(0.0258)\end{array}$ & $\begin{array}{l}0.9370^{* * *} \\
(0.0263)\end{array}$ \\
\hline $\mathrm{N}$ & 42162 & 42162 & 26489 & 26489 \\
\hline $\mathrm{R}^{2}$ & 0.6447 & 0.6495 & 0.6960 & 0.6998 \\
\hline
\end{tabular}

Notes: ${ }^{* * *}$ significant at the 0.01 level; ${ }^{* *}$ significant at the 0.05 level; * significant at the 0.10 level. The reference for the household head is a Swiss with low education level.

\section{Conclusions}

We found evidence of segregation, prejudice and discrimination against foreigners, particularly the less educated ones, in the two largest rental markets of Switzerland, those of Zurich and Geneva. However, the magnitude of these biases is not very large, except for low education foreigners who pay between 5 and 7 per cent more on average for the same dwelling than low education Swiss. Without distinguishing by education level, the penalty imposed on foreigners is about 2 per cent. That may seem little considering anecdotal evidence of relatively high rents charged for lousy housing to recent low-income immigrants or, in a different category, of astronomical rents paid by highly qualified foreign employees of international firms. Our results do not contradict that anecdotal evidence but they remind us that the largest share of foreigners have been living in Switzerland 
for many years and are well integrated. Remember also that our discrimination indicator is quality adjusted, i.e. foreign specialists can still pay a lot for housing, but they do not necessarily pay significantly more than Swiss specialists for the same type of flats.

Of course, reality is more complex than what could be captured by simple proportions of foreigners per hectare or a few coefficients on nationality dummies in hedonic price regressions. This is a first step to a more thorough analysis that is made possible by the growing wealth of data that we were able to collect. In particular, since our results show that foreigners with low education tend to live in neighbourhoods of relatively worse unobserved quality both in Geneva and Zurich, in a forthcoming companion paper we are more precisely characterising the differentials in the living conditions between socio-economic groups. Indeed, even if our results show no strong price discrimination against foreigners, it would still seem unfair if foreign households occupied systematically dwellings of lower quality in less attractive neighbourhoods or if they lived in more crowded situations and had to spend a higher share of their income for housing (e.g. Thalmann, 2003). This will also allow for a broader picture about environmental justice. But more fundamentally, it would be relevant to develop a structural model taking into account the possibility of a market segmentation based on environmental quality and to test whether or not foreigners - particularly the less educated ones - have a higher probability to live in "low" quality neighbourhoods.

Our results shed light on a few facets of segregation, prejudice and discrimination. In addition, they show that household characteristics have their place in a hedonic price equation, but that the coefficients estimated for the traditional dwelling and neighbourhood characteristics are not significantly biased if they are left out.

\section{References}

Arend, M. (1991), "Housing Segregation in Switzerland", in E. D. Huttman (ed.), Urban Housing Segregation of Minorities in Western Europe and the United States, Duke University Press, Durham and London.

Arend, M., A. Kellerhals Spitz and T. Mächler (1990), «Groupes défavorisés sur le marché du logement: Problèmes et mesures», Bulletin du logement 45, Office fédéral du logement, Bern, Switzerland.

Bajari, P., and M. E. Kahn (2005), "Estimating Housing Demand with an Application to Explaining Racial Segregation in Cities", Journal of Business and Economic Statistics, 23(1), pp. 20-33. 
Bajari, P., and M. E. Kahn (2008), "Estimating Hedonic Models of Consumer Demand with an Application to Urban Sprawl", in A. Baranzini, J. Ramirez, C. Schaerer and P. Thalmann (eds), Hedonic Methods in Housing Markets: Pricing Environmental Amenities and Segregation, New York, pp. 129-158.

Banfi, S., M. Filippini and A. Horehajova (2008), "Valuation of Environmental Goods in Profit and Non-Profit Housing Sectors: Evidence from the Rental Market in the City of Zurich", This Volume.

Baranzini, A., and J. V. Ramirez (2005), "Paying for Quietness: The Impact of Noise on Geneva Rents", Urban Studies, 42(4), pp. 633-646.

Baranzini, A., C. Schaerer, J. Ramirez and P. Thalmann (2006), "Feel it or Measure it. Perceived vs. Measured Noise in Hedonic Models", Cahier de recherche HES-SO/HEG-GE/C-06/7/1-CH, Haute Ecole de Gestion, Geneva, Switzerland, available at SSRN: http://ssrn.com/abstract=937259.

Baranzini, A., and C. Schaerer (2007), "A Sight for Sore Eyes: Assessing the Value of View and Landscape Use on the Housing Market", Cahier de recherche HES-SO/HEG-GE/C-07/1/1-07, Haute Ecole de Gestion, Geneva, Switzerland, available at SSRN: http://ssrn.com/abstract=981189.

Baranzini, A., J. Ramirez, C. Schaerer and P. Thalmann (eds) (2008), Hedonic Methods in Housing Markets. Pricing Environmental Amenities and Segregation, New York.

Bayer, P., F. Ferreira and R. McMillan (2007), "A Unified Framework for Measuring Preferences for Schools and Neighbourhoods", Journal of Political Economy, 115(4), pp. 588-638.

Bayer, P., and R. McMillan (2008), "Distinguishing Racial Preferences in the Housing Market: Theory and Evidence”, in A. Baranzini, J. Ramirez, C. Schaerer and P. Thalmann, op. cit., pp. 225-244.

Becker, G. (1957), “The Economics of Discrimination”, University of Chicago Press, Chicago.

Freeman, A. M. (1993), "The Measurement of Environmental and Resource Values: Theory and Methods", Resources for the Future, Washington, DC.

Galster, G. C. (1977), "A Bid-Rent Analysis of Housing Market Discrimination", American Economic Review, 67(2), pp. 144-155.

Halvorsen, R., and R. Palmquist (1980), "The Interpretation of Dummy Variables in Semilogarithmic Equations", American Economic Review, 70(3), pp. 474-475.

Harding, J., J. R. Knight and C. F. Sirmans (2003), "Estimating Bargaining Effects in Hedonic Models: Evidence from the Housing Market", Real Estate Economics, 31: 601-622. 
Harris, D. R. (1999), "Property Values Drop when Blacks Move In, Because ...: Racial and Socioeconomic Determinants of Neighbourhood Desirability", American Sociological Review, 64(3), pp.461-479.

Harrison, M., I. Law and D. Phillips (2005), "Migrants, Minorities and Housing: Exclusion, Discrimination and Anti-Discrimination in 15 Member States of the European Union", European Monitoring Centre on Racism and Xenophobia, Vienna, Austria.

Heye, C., and H. Leuthold (2004), „Segregation und Umzüge in der Stadt und Agglomeration Zürich“, Gruppe sotomo, Geographisches Institut Universität Zürich.

Huissoud, T., S. Stofer, A. Cunha and M. Schuler M. (1999), «Structures et tendances de la différenciation dans les espaces urbains en Suisse», Rapport de recherche no 145, Institut de recherche sur l'environnement construit, EPFL, Lausanne, Switzerland.

Huissoud, T., S. Stofer and A. Cunha (1999), «L'influence régionale sur la répartition spatiale des populations", in Structures et tendances de la différenciation dans les espaces urbains en Suisse, Rapport de recherche no 145, Partie II, Institut de recherche sur l'environnement construit, EPFL, Lausanne, Switzerland.

Huttman, E. D. (1991), "Housing Segregation in Western Europe: An Introduction", in E. D. Huttman, W. Blauw and J. Saltman (eds), Urban Housing Segregation of Minorities in Western Europe and the United States, Durham and London.

Kestens, Y., M. Thiérault and F. Des Rosiers (2004), "Links between Residential Choice Criteria and Property Values: Some Evidence Using Correspondence Analysis and Hedonic Modelling", paper presented at 11th annual European Real Estate Society Conference, Milan, 2-5 June, Mimeo.

Kiel, K., and J. E. Zabel (1996), "House Price Differentials in U.S. Cities: Household and Neighborhood Racial Effects", Journal of Housing Economics 5, pp. 143-165.

Kiel, K. A., and J. E. Zabel (2004), "Location, Location, Location: The 3L Approach to House Price Determination”, Discussion paper, Center of Economic Studies CES04-06, Washington DC.

King, T. A., and P. Mieszkowski (1973), "Racial Discrimination, Segregation, and Price of Housing", Journal of Political Economy, 81(3), pp. 590-606.

Knight, J. R. (2008), "Hedonic Modeling of the Home Selling Process", in A. Baranzini, J. Ramirez, C. Schaerer and P. Thalmann, op. cit., pp. 39-54.

Malpezzi, S. (2002), "Hedonic Pricing Models: A Selective and Applied Review", in Kenneth Gibbs K. and O'Sullivan A. (eds), Housing Economics: Essays in Honor of Duncan Maclennan, Blackwell, London. 
Myers, C. K. (2004), "Discrimination and Neighbourhood Effects: Understanding Racial Differentials in US Housing Prices", Journal of Urban Economics, 56, pp. 279-302.

Office Cantonal de la population (OCSTAT) (2005), «Portrait statistique des étrangers vivant à Genève: Résultats du recensement fédéral de la population et autres sources», Etudes et documents 37, Geneva, Switzerland.

OfFICE FÉdÉRAL DE LA STATISTIQUe (OFS) (2006), «La population étrangère en Suisse», Série Statistique de la Suisse, OFS, Neuchâtel, Switzerland.

OfFice fÉdÉral Du Logement (OFL) (2003), «Proportion de logements en propriété en comparaison internationale», http:///www.bwo.admin.ch/dokumentation/00101/00105/ index.html

Palmquist, R. B. (1999), "Hedonic Models", in J. C. J. M. van den Bergh (ed.), Handbook of Environmental and Resource Economics, Cheltenham, pp. 765-776.

Rosen, S. (1974), "Hedonic Prices and Implicit Markets: Product Differentiation in Pure Competition", Journal of Political Economy, 82, pp. 34-55.

Schaerer, C., A. Baranzini, J. V. Ramirez and P. Thalmann (2007), "Using the Hedonic Approach to Value Landscape Uses in an Urban Area: An Application to Geneva and Zurich", Economie Publique - Public Economics, 20(1), pp. 147-167.

Schaerer, C., and A. Baranzini (2008), "Where and How Do People Live? Segregation in Geneva and Zurich Housing Markets", Cahier de recherche HES-SO/HEG-GE/C--08/11/1--CH, Haute Ecole de Gestion, Geneva, Switzerland,

Schelling, T. (1971), "Dynamic Models of Segregation”, Journal of Mathematical Sociology, 1, pp. 143-86.

Schuler, M. (1999), "La différenciation selon les types communaux», in Structures et tendances de la différenciation dans les espaces urbains en Suisse, Rapport de recherche no 145, Partie VII, Institut de recherche sur l'environnement construit, EPFL, Lausanne, Switzerland.

Swiss Noise Abatement Ordinance (1986), SR 814.41, AS 1987 338, Bern, Switzerland.

TAYLOR, L. O. (2008), "Theoretical Foundations and Empirical Developments in Hedonic Modeling", in A. Baranzini, J. Ramirez, C. Schaerer and P. Thalmann, op. cit., pp. 15-38.

Thalmann, P. (1987), «Explication empirique des loyers lausannois», Swiss Journal of Economics and Statistics, 123(1), pp.47-69.

Thalmann, P. (2003), “'House Poor' or Simply 'Poor'?”, Journal of Housing Economics, 12(4), pp.291-317. 
Wanner, P. (2004), «Migration et intégration: Populations étrangères en Suisse», Office fédéral de la statistique, Neuchâtel, Switzerland.

Wüest \& Partner (2007), „Immo-Monitoring 2008/1: Analysen und Prognosen Fokus Wohnungsmarkt", Zürich, Switzerland.

Yinger, J. (1978), "The Black-White Price Differential in Housing: Some Further Evidence", Land Economics, 54(2), pp. 187-206.

ZABEL, J. E. (2008), "Using Hedonic Models to Measure Racial Discrimination and Prejudice in the U.S. Housing Market", in A. Baranzini, J. Ramirez, C. Schaerer and P. Thalmann, op. cit., pp. 177-202.

\section{SUMMARY}

The Geneva and Zurich housing markets are characterised by high proportions of foreigners and a large share of rental housing. This provides ideal conditions for testing whether foreigners pay more for the same quality of housing than Swiss households and whether flats in neighbourhoods with higher proportions of foreigners rent at a discount. Hedonic price equations using a rich dataset on dwellings and their occupants yield evidence of such discrimination and prejudice. They also suggest more complex relationships between tenant nationality, housing and neighbourhood quality, and rents. 